\title{
Formação em Terapia Ocupacional na Interface das Artes e da Saúde: a experiência do PACTO
}

\section{Education in Occupational Therapy in the Art \& Health Interface: the PACTO experience}

\author{
Eliane Dias de Castro" ${ }^{1}$, Erika Alvarez Inforsato ${ }^{2}$, Andréa do \\ Amparo Carotta De Angeli², Elizabeth M. F. Araújo Lima ${ }^{1}$
}

CASTRO, E. D. de; INFORSATO, E. A.; ANGELI A. do A. C. de; LIMA, E. M. F. A. Formação em Terapia Ocupacional na interface das artes e da saúde: a experiência do PACTO. Rev. Ter. Ocup. Univ. São Paulo, v. 20, n. 3, p. 149-156, set./dez. 2009.

\begin{abstract}
RESUMO: Este artigo apresenta o trabalho de formação oferecido na Graduação em Terapia Ocupacional desenvolvido pelo Laboratório de Estudos e Pesquisa Arte, Corpo e Terapia Ocupacional da FMUSP. O Laboratório realiza atividades de ensino e pesquisa, no campo didático-assistencial, nos atendimentos grupais e individuais para populações heterogêneas através do Programa Permanente Composições Artísticas e Terapia Ocupacional (PACTO) e em parcerias com projetos que se constituem na interface arte-saúde. As experiências dos estudantes são acolhidas e elaboradas em discussões de equipe, supervisões semanais, grupo de estudos e seminários de aprofundamento temático. A formação oferecida habilita os estudantes para: a compreensão e a construção de práticas na interface arte/saúde; a problematização das abordagens na interface arte/saúde nos espaços de assistência em saúde e nos espaços culturais; a compreensão das relações institucionais e sociais e dos processos de transformação das instituições; a reflexão sobre a participação do terapeuta ocupacional nas políticas culturais e nas políticas de humanização em saúde. Elegemos relatar e pontuar aspectos do trabalho efetuado nos últimos anos (2003-2008) no qual algumas estratégias de ensino foram consolidadas e evidenciaram seus efeitos na formação dos estudantes e no exercício profissional. No campo da Terapia Ocupacional verifica-se uma ampliação das possibilidades de atuação profissional vinculadas ao campo da produção cultural, em projetos transdisciplinares voltados para construção de redes sociais inclusivas, com a participação coletiva e a produção de subjetividade.
\end{abstract}

DESCRITORES: Terapia Ocupacional. Educação. Arte. Capacitação de recursos humanos em saúde.

\footnotetext{
${ }^{1}$ Docente do Curso de Terapia Ocupacional do Departamento de Fisioterapia, Fonoaudiologia e Terapia Ocupacional da FMUSP.

${ }^{2}$ Terapeuta Ocupacional do Curso de Terapia Ocupacional do Departamento de Fisioterapia, Fonoaudiologia e Terapia Ocupacional da FMUSP.

Endereço para correspondência: Rua Cipotânea, 51. CEP: 05508-900 - São Paulo / SP. E-mail:elidca@usp.br / beth.lima@usp.br
} 


\section{INTRODUÇÃO}

$\mathrm{O}$ Laboratório de Estudos e Pesquisa Arte e Corpo em Terapia Ocupacional desde sua instauração, em 1996, tem implantado projetos para a experimentação no campo de interface entre as artes, $o$ corpo e a TO, bem como a expansão de convênios e parcerias com projetos afins, situados em territórios acadêmicos e extra-acadêmicos. A relação com as atividades de ensino e de formação deste Laboratório é o tema principal deste texto, privilegiando-se as disciplinas de ensino prático do currículo da graduação em Terapia Ocupacional (TO) da FMUSP oferecidas pelo Laboratório, em seus últimos anos de funcionamento (entre 2003-2008), nos quais algumas estratégias puderam consolidar-se após as acomodações iniciais, e evidenciar seus efeitos na formação de terapeutas ocupacionais que posteriormente passaram, em sua maioria, a exercer a profissão na rede pública de saúde.

Essas disciplinas ocorrem numa atuação híbrida que pressupõe o delineamento de um dispositivo clínicoartístico-cultural no bojo de um projeto docente-assistencial que se constrói no enfrentamento de questões decorrentes do entrecruzamento população atendida, estudantes, docentes e técnicos. Para além das especializações das áreas de atuação, o que se busca responder são demandas de construção de conhecimento para a Terapia Ocupacional, considerando conjuntamente o cuidado à população $\mathrm{e}$ as temáticas a ele relacionadas no tangenciamento com outros campos do conhecimento. Este é um importante desafio para a Terapia Ocupacional na contemporaneidade, pois na construção cotidiana das relações sociais e profissionais, cada vez mais os terapeutas ocupacionais são convocados a atuar num exercício fundamentalmente transdisciplinar.

As ações desenvolvidas na proposta formativa do Laboratório constroem-se no entrecruzamento de disciplinas e práticas, seguindo o pressuposto do desenvolvimento científico contemporâneo proposto por Morin (1992) como aquele que exige a superação dos abismos entre as ciências da vida e do homem. Aqui há um trabalho para a integração entre conhecimentos biológicos, psicológicos, antropológicos, sociais e filosóficos, e a construção de áreas que o autor denomina de biopsicoantropossociais, na tentativa de aglutinar elementos indissociáveis para uma perspectiva mais integrada para a produção de conhecimento.

De outro modo, mas seguindo uma mesma orientação, que busca aproximar zonas de conhecimento em relações de transversalidade e justaposição, Maturana e Varela (2001) propõem uma abordagem transdisciplinar em que enfatizam que o conhecimento é construído pelo homem e por suas interações com o mundo, numa relação de simultaneidade onde: o homem constrói o mundo durante sua vida, ao mesmo tempo em que é por ele construído, de forma interativa, singular, criativa e compartilhada. Este modo de pensar, orienta para uma disposição humana aberta a uma ação responsável frente ao mundo em que se vive. E demanda daquele que se propõe conhecer, uma atitude ativa frente ao processo de construção do conhecimento, na qual todo ato de conhecer faz surgir o próprio mundo que se está conhecendo. Conhecer é um ato de engendramento do próprio conhecimento e do mundo que produz sua necessidade. A observação cuidadosa, a curiosidade, a experimentação, a crítica e a reflexão são elementos que compõem este ato.

Neste sentido, a formação para atuar em projetos que se constroem na interface das Artes e da Saúde busca preparar para ações com populações em situação de vulnerabilidade, dirigidas à mediação das demandas com o campo social e cultural. Isto implica um conjunto de conhecimentos e habilidades múltiplos e interdisciplinares, composto por traços do campo das artes, da clínica, da educação e da saúde, para uma construção constante de estratégias de inscrição e participação sociocultural do próprio profissional terapeuta ocupacional e da população atendida.

Nesta perspectiva situa-se o projeto didáticoassistencial do PACTO, que articula, no campo da TO, proposições da Reabilitação Psicossocial (SARRACENO, 1999) a paradigmas ético-estético-políticos (GUATTARI, 1992), que buscam construir outros modos de vida para a população atendida. Instaura-se assim uma ecologia onde há organização de tempo e espaço para acolher várias formas de fazer, comunicar, criar, inventar e conhecer as artes, de modo a possibilitar que a medida humana se expresse em sua heterogeneidade. A partir das abordagens e metodologias que atravessam o trabalho com o corpo e com as artes e com as diretrizes que integram práticas clínicas e sociais no campo da Terapia Ocupacional, organizou-se um conjunto conceitual inicial e foram estabelecidas as primeiras estratégias para realização dos atendimentos do PACTO.

À medida que foram sendo realizadas as triagens e organizados os grupos de atendimento, foi possível receber estudantes e bolsistas de graduação e pós-graduação e profissionais para compor e trabalhar com a equipe de implantação do projeto. Numa interação constante, o Projeto didático-assistencial tem sido formado coletivamente por usuários, estudantes, terapeutas ocupacionais e docentes, instaurando um processo formativo que produz conexões inéditas no circuito artístico-cultural e, também, para as áreas que tangenciam a produção da saúde. 
A configuração de uma equipe para gerenciar esta proposta didático-assistencial exigiu uma afinação em dois níveis que se integram constantemente. Ao nível didático, privilegia-se a formação do terapeuta ocupacional com dispositivos de coordenação e supervisão das ações, bem como com estruturas de acolhimento e continência dos temas disparados pelas experiências de aproximação com a população, com o campo de atividades e com os serviços e equipes de saúde e cultura. Ao nível assistencial, enfatiza-se o mapeamento das demandas orientadas para este campo de inscrição sociocultural, para a circunscrição das possibilidades de atendimento, dimensionamento das atividades oferecidas, invenção freqüente de dispositivos de suporte e sustentabilidade aos projetos iniciados e em desenvolvimento.

A constituição de um espaço de ensino e prática profissional e do projeto didático-assistencial no campo de interface entre as Artes e a Saúde é favorecida pelo fato de poder situar-se no âmbito da USP, com a presença de docentes e técnicos terapeutas ocupacionais e suas atividades. Neste sentido, ensino, pesquisa e extensão universitária foram articulados imprimindo ao projeto a potência de ações e reflexões inovadoras e consistentes.

O movimento da equipe de coordenação e gestão do PACTO é o de ampliar o universo de pensar e de agir do terapeuta, a partir de um processo gradual de vivências e de construção do conhecimento, articulando aspectos conceituais e empíricos, enraizados numa proposta concreta de atenção à comunidade. Considera-se que "há a necessidade de emancipação cultural do próprio terapeuta ocupacional para que sua clínica pertença à contemporaneidade, e nesse sentido auxilie seu paciente nela conviver" (CASTRO, 2000, p. 11). Desta forma, a experiência prática engendrada também vem revitalizar a participação sociocultural das populações atendidas em TO, multiplicando possibilidades de atenção e melhora das condições de respostas a suas demandas.

Compõe ainda esta proposta de formação a colaboração em projetos que têm parceria com o Laboratório e que se situam na interface arte-saúde, utilizando propostas com artes plásticas e artes do corpo no trabalho com populações em situação de vulnerabilidade social. Esta cooperação visa possibilitar ao estudante a inserção no território da cultura e dos serviços de saúde, o contato com diversas linguagens artísticas, junto a populações com demandas e problemáticas complexas e múltiplas e com um contexto profissional mais amplo constituído por profissionais das artes, da cultura, da saúde, da educação, além de modelos institucionais diversificados.

\section{MÉTODO}

Diante da caracterização híbrida deste projeto didáticoassistencial, a produção de uma metodologia de trabalho tem sido contemporânea a sua própria aplicação, portanto, conforme as experiências desdobram novas formas de atendimento à população, de constituição de parcerias e de formação de estudantes de TO, os procedimentos para dar consistência e sistematização a estas formas vão simultaneamente configurando-se.

O ensino prático oferecido pelo Laboratório atende às demandas curriculares, com variação de quantidade de matrículas (entre 3 e 6 estudantes), que pressupõem cargas horárias semestrais distintas, distribuídas em duas disciplinas:

- estágio supervisionado, correspondente aos estudantes do $4^{\circ}$ ano com 420 horas distribuídas numa grade composta por atividades comuns (grupo de estudos, supervisão, reuniões) e atividades específicas junto aos projetos parceiros e do PACTO; e

- práticas supervisionadas, correspondentes aos estudantes do $2^{\circ}$ e $3^{\circ}$ anos, com 90 horas distribuídas em atividades comuns (supervisão e grupos de estudos) e uma atividade de acompanhamento de projetos privilegiando aqueles coordenados por terapeutas ocupacionais.

A cada semestre, o Laboratório organiza sua disponibilidade de vagas em cada projeto, em função do momento de seus funcionamentos. E os estagiários são alocados considerando o entrecruzamento de questões, sejam nas diferentes linguagens artísticas (coral, teatro, oficinas de dança, ateliês de artes plásticas), sejam nas diferentes faixas etárias (idosos, crianças, adultos).

Em relação à formação, algumas instâncias de interlocução foram criadas, de modo a acolher as experiências dos estagiários em discussões do projeto didático-assistencial, para a coordenação (planejamento, distribuição e avaliação) das atividades do Laboratório. Com vistas a um trabalho com a implicação dos estudantes na construção deste campo na perspectiva da TO são realizadas reuniões de equipe, supervisões semanais, grupo de estudos, acompanhamento de diários de campo e seminários de aprofundamento temático.

\section{Reuniões de equipe}

Para alinhavar as várias dimensões de relações institucionais e oferecer aos estudantes acesso aos modos de funcionamento e seus respectivos referenciais, com os elementos que compõem a rede de contatos e realizações de projetos do Laboratório, são organizadas reuniões de 
equipe em composições diversas. Com um número maior de participantes, são realizadas reuniões quinzenais de toda a equipe, com pautas de discussão clínicas, didáticas e administrativas, coletivamente, docentes, terapeutas ocupacionais, bolsistas, estagiários e representantes dos projetos parceiros do Laboratório, debruçam-se sobre questões relacionadas ao acompanhamento e aprofundamento das ações propostas e realizadas no PACTO e nos projetos conveniados, considerando aspectos clínicos, sociais, políticos e operacionais. Este é um momento de reflexão e de possibilidade de olhar, com adequado distanciamento, o envolvimento produzido nos encontros com as equipes, com as instituições e com a população atendida. Isto requer o acompanhamento e enfrentamento de questões, ora pontuais, ora amplas e complexas, que só podem ser respondidas através de uma observação cuidadosa frente àquilo que emerge no cotidiano das práticas e que se apresenta nessas reuniões.

Em grupos mais reduzidos, realizam-se reuniões semanais das mini-equipes de cada projeto, nelas profissionais, estagiários e bolsistas discutem o andamento das atividades propostas, a organização dos materiais e dos espaços, as demandas e situações emergentes no dia-a-dia dos atendimentos. Busca-se estruturar estes encontros de forma a potencializar o diálogo e a colaboração e estabelecer um ambiente de trocas entre todos os envolvidos. O espaço aberto, organizado a partir de pautas sugeridas por todos os participantes dos grupos e problematizadas pelos coordenadores, instaura uma revisão de acontecimentos de múltiplas ordens: subjetivos, relacionais, criativos, técnicos, informativos, participativos, culturais, etc.

Num aprendizado cotidiano depara-se com necessidades que requerem de toda equipe muita atenção e grande responsabilidade na condução dos processos dos grupos e da população atendida. As demandas que emergem nessas práticas exigem uma nova orientação ético-estéticopolítica que engendra uma renovação ética e uma produção e apreensão de conhecimento coletivas e constantes.

Nas composições compartilhadas por usuários e terapeutas, "uma abertura para a passagem, para o acontecimento, no encontro com as singularidades que emergem da população que atendemos" (INFORSATO, 2005 , p. 39) implica a adoção e a construção de uma nova postura ética que atravessa todos os momentos deste encontro.

Essa nova postura ética aponta para:

uma relação de composição, (...) um encontro de heterogeneidades que busca se manter heterogêneo do princípio ao fim da relação, promovendo o mútuo fortalecimento das inteligências em conexão; (...) cada parte é ao mesmo tempo agente e teatro da relação (SANT'ANNA, 2001, p.96).

\section{Grupo de estudos}

A necessidade de oferecer e operar com referências conceituais no próprio decorrer do ensino prático, no sentido de exigir um rigor na compreensão e construção discursiva para o entendimento e a divulgação de processos de trabalho, configurou mais um elemento no processo de formação dos estudantes no Laboratório, na forma de um trabalho quinzenal de grupo de estudo, a partir de uma bibliografia selecionada de acordo com as atividades e relações desenvolvidas durante o período de estágio, considerando as experiências clínicas, políticas e institucionais. Através do grupo de estudos, o estudante entra em contato com um arcabouço conceitual, em constante construção e atualização, que acompanha, sustenta e delineia um raciocínio clínico orientador das ações desenvolvidas.

As conversas e debates proporcionados pela leitura e discussão dos textos nesses encontros possibilitam aos estagiários e bolsistas exercícios de pensamento que entrecruzam-se com as experiências de atendimento à população (nas ações do PACTO e de suas parcerias). Com isso, oferece-se aos estudantes a possibilidade de conhecerem e de acompanharem pesquisas realizadas pelos docentes e terapeutas ocupacionais envolvidos nos projetos do Laboratório e de compartilharem esses trabalhos num estudo atualizado da bibliografia proposta.

Para tanto, foram engendradas algumas metodologias, a saber, realização de leituras e estudos de textos, preparação e apresentação de seminários e estudos temáticos. Um eixo conceitual é organizado para cada grupo de estagiários e bolsistas e este conteúdo é revisto e atualizado semestralmente, a partir das sugestões e necessidades dos estudantes, dos docentes e terapeutas ocupacionais supervisores, numa operação processual, com um pensamento em trânsito que acompanha o movimento de um trabalho em desenvolvimento.

O solo conceitual no qual se sustenta esta experiência foi sendo preparado à medida que os profissionais envolvidos na implantação do PACTO realizavam suas pesquisas de teses e dissertações, e uma extensa bibliografia das áreas que tangenciam as fronteiras das Artes, da Terapia Ocupacional, da Educação, da Filosofia e da Saúde, foi sendo estudada e selecionada. Isto envolveu temáticas pautadas na contextualização histórico-conceitual da utilização das atividades artísticas no campo da saúde, no conhecimento de aspectos relacionados à história das artes, na construção de conhecimento técnico e metodológico nestes campos, nas produções textuais recentes da TO que se aproximam 
das propostas do PACTO e, em uma contextualização mais ampla, do encontro entre práticas clínicas e sociais (CASTRO et al., 2005; 2007).

Estas questões que nos remetem a uma circunstancialização do presente - cenário de desordens e de instabilidade, em que operam tendências contraditórias, com lógicas capitalistas. Este projeto de formação pressupõe que as iniciativas de solidariedade e universalização da cidadania, não são a tendência dominante e que acompanhar as ações de sujeitos com histórias complexas nos remete a um campo de inventividade e de heterogeneidade e relacionase à construção do acesso às múltiplas informações que os diferentes campos do conhecimento podem proporcionar (CASTRO, 2001; LIMA, 2003, 2005; INFORSATO, 2005; ANGELI, 2008).

Nesta construção, a escuta organizada das necessidades da população atendida operou como força motriz dos ajustes dos conteúdos estudados, fazendo com que novos cenários de conhecimento fossem pesquisados e introduzidos nos estudos. Nesta relação com as pessoas atendidas compreende-se que todos os fios, que conduziram para a construção e formação no PACTO, passam inegavelmente por lugares da ética, da construção dos direitos e das políticas em saúde que direcionam ou podem orientar este encontro. Numa costura capaz de reforçar as passagens entre autonomia pessoal e vínculo social, percebe-se o ser vivo em constituição, em processo, "tendo como princípio as conexões que o constituem ao longo de sua existência" (SANT'ANNA, 2001, p. 88).

Os campos conceituais que envolvem e enraízam esta prática apontam para a extensão do tema e para a pluralidade de demandas que emergem no campo assistencial, em especial pelas características da população atendida em TO, hoje, no Brasil. Neste processo, adaptações de saberes e práticas foram realizadas de acordo com as necessidades e questões apresentadas pelos sujeitos atendidos, "o que implica numa construção gradual, artesanal, de desconstrução de problemas e de recomposição, ressignificação, complexificação de possibilidades e de entrada no circuito social" (CASTIGLIONI et al., 2004, p.65).

\section{Grupo de supervisão dos estagiários}

A partir das vivências nos atendimentos e das afetações engendradas pela relação com a população atendida, um cuidadoso trabalho de supervisão é realizado. Em encontros semanais os estagiários são acolhidos e acompanhados no aprendizado da construção de vínculos e de condução de processos em projetos voltados à produção de saúde, bem como na reflexão sobre as questões que emergem diante do contato com as estruturas institucionais e com a dinâmica do Projeto didático-assistencial.

Na supervisão é oferecido aos estudantes um trabalho de sustentação e continência para que possam desenvolver um entendimento e um modo de trabalhar, pesquisar procedimentos e localizar núcleos de interesse no âmbito da própria graduação, que permita a construção de uma reflexão sobre sua própria prática e, quando possível, o acionamento de novos processos de subjetivação que, nesta disposição conjunta com os terapeutas ocupacionais em posição de escuta, possam vir a compor planos de consistência para a profissão.

\section{Diário de campo}

O dispositivo de construção de diários de campo agregou-se ao projeto de formação do PACTO para acentuar dimensões de experimentação estética que conectassem o estagiário com seu material vivencial, durante o período de estágio, para utilizá-lo numa melhor elaboração de sua profissionalização. Foram assim denominados em função dos cadernos de artistas, um procedimento usual no campo das artes, quando artistas efetuam anotações diárias em suportes e linguagens diversificadas, que permitem agregar elementos de origens múltiplas que atravessam seu diaa-dia durante um determinado processo. Transportando este procedimento para os estudantes de $\mathrm{TO}$, configurouse um outro modo de fazer registros que favoreceria um deslocamento da exclusividade da expressão escrita predominante nos registros de experiências de estágio em relatórios, que muitas vezes redunda em automatizações acadêmicas. Nestes diários de campo, os estagiários são convidados a efetuar um exercício de apreensão ampliada de sua trajetória no estágio, considerando este registro como um suporte de toda experiência suscitada durante o tempo e espaços neste percurso.

A temática dos estágios, relacionada a uma entrada no campo de interface entre as artes e a saúde, pressupõe uma sensibilização às questões destes universos de conhecimento e práticas, colocando o estudante em muitas situações em que a população atendida está em posição de produção inventiva, relacionando-se com os diversos caminhos possíveis para a expressão: textos, pinturas, conversas, comidas, esculturas, desenhos, músicas, danças, teatro, vídeo etc. Assim, as sensações são uma referência fundamental neste processo, e para os diários de campo elas funcionam como ponto de partida, com o objetivo de construir um território que possa dar sustentação às experiências deste momento da vida de cada estagiário, de modo a tocar a fronteira entre as artes e a saúde na formação acadêmica, no âmbito da educação.

A idéia de acionar sensações está relacionada não só 
aos sentidos (olhares, toques, cheiros, escuta, sabores), mas também ao que constitui os lugares de pensamento, onde este possa ganhar consistência e proliferar. A sensibilização e a coleta de material se dá através das vivências diretas do estágio bem como de todas as outras que a elas podem associar-se de modo livre e atemporal (filmes já vistos, encontros fortuitos, textos, histórias particulares, experiências estéticas, vivências de horror, dimensões de participação política, etc).

A proposta é de que se constituam camadas, justaposições, aquém e além das conexões entre os elementos que compõem a vida do estudante. Evidentemente não se trata de um trabalho clínico, tampouco artístico, entretanto estas aproximações estão sempre colocadas - em seu sentido de análise e deslocamento (em relação à clínica) e de práxis e obra (em relação às artes). Conforme vão produzindo os diários de campo, a construção destas distâncias em relação à clínica e às artes habilitam o terapeuta ocupacional em formação para a delicadeza que compõe cada vida, e interrogam sobre como manejar seus elementos a partir dos lugares que se ocupa. No caso dos diários de campo este lugar é a graduação, e a convergência de todos os elementos tem o compromisso de voltar-se ao pensamento da prática profissional em TO.

Na prática, cada diário de campo é desenvolvido em 3 etapas, que são entregues em datas fixadas previamente, e neles devem constar: descrições das situações de estágio; citações, referências, grafismos, pinturas, colagens, cópias, fotos, dobras, texturas etc, que mantenham algum tipo de relação com as vivências do estágio; elaborações, associações e comentários que apresentem sua expansão e crescimento profissional na avaliação e proposição de saídas diante das vivências do estágio com equipes, população atendida, instituições, coordenações, espaços sociais, exercícios políticos etc.

A cada semestre, são construídos modos de partilha dos diários produzidos que se apresentam em formatos múltiplos e heterogêneos (tubos, pastas, caixas, móbiles, estruturas, biscoitos, vídeos, fotos, livros, bolos, poesias, álbuns, músicas, registros de performances etc). A interlocução é feita no espaço de supervisão com devolutivas de apreciação formal feitas coletivamente sob a orientação da supervisora, que buscam compreender a trajetória daquilo que necessita encontrar formas de expressão, e oferecer apontamentos sobre o que parece funcionar bem, o que não, e disponibilizar-se a pensar junto como colocar em marcha, como por em movimento as marcas das vivências do estágio. É um trabalho arriscado e sutil, que demanda uma cumplicidade muito grande do grupo de estagiários, da supervisora e da equipe de coordenação do estágio, que apresenta situações-limite, e que têm sido, em geral, uma experiência de intensidade, motivadora e constituinte de uma oportunidade afirmativa para a elaboração das questões de estágio aos estudantes que vem ao encontro do PACTO.

\section{Assessoria institucional}

Como um lugar de cuidado com as relações de trabalho e com as questões institucionais, encontros mensais são realizados com um assessor externo à Universidade, selecionado pela equipe de coordenação do Laboratório considerando profissionais afinados com o universo de políticas públicas de saúde e o território universitário, para que o processo de construção de um entendimento ampliado dos acontecimentos relacionados ao PACTO possa ocorrer. Logo no segundo ano de criação do Programa foi-se tecendo conjuntamente com estes assessores costuras necessárias para afirmar a proposta de atendimento e fornecer para toda a equipe um lugar de escuta e de reflexão. Estes encontros são reparadores de diversas situações e acontecimentos, pois aumentam a troca entre a equipe e oferecem aos seus componentes uma nova oportunidade de entendimento do vivido no âmbito das relações profissionais.

Ao aprofundar passo a passo questões que surgem, constroem-se processos compartilhados, e possibilidades de revisar as formas de intervenção propostas, adequando necessidades aos recursos e potencialidades da equipe. Afinar estes elementos traz ao conjunto das pessoas envolvidas a sensação de acompanhamento de um trabalho criativo. As reflexões engendradas vivificam um processo de autoorganização da equipe e afinam suas produções com os estudantes, com as pessoas atendidas, com a instituição e cria maior plasticidade na relação entre o próprio grupo de trabalho.

\section{RESULTADOS E CONSIDERAÇÕES FINAIS}

As ações acima descritas definem os contornos de uma proposta de formação no âmbito de um programa didáticoassistencial que tem se constituído como lugar de cuidado, de fazer, de pertencimento, de composição e de aprendizado, - lugar de criação e de resistência para pensar a produção cotidiana da vida.

Os estudantes que participam dessas disciplinas são habilitados para: a compreensão de uma práxis na interface arte e saúde; as implicações desta inovação e a elaboração de questões referentes à construção e sustentação de dispositivos clínico-artístico-culturais; a problematização das abordagens da TO em espaços de saúde e de cultura; a compreensão das múltiplas dimensões das relações institucionais e sociais e dos processos de transformação das instituições; e as práticas contemporâneas em TO na comunidade através do uso de 
atividades artísticas.

Ao longo destes anos de experiência com a formação de estudantes da graduação nas configurações aqui apresentadas, o crescimento dos estudantes ficou evidenciado tanto em sua responsabilização com a população atendida, quanto na compreensão da importância do terapeuta ocupacional na sustentação de projetos inovadores para o exercício da participação sociocultural.

A perspectiva adotada possui ressonâncias importantes com as políticas de humanização em saúde e as políticas públicas de saúde e cultura, que abriram um entrelaçamento dos fazeres práticos e conceituais relacionados às suas diretrizes e afirmaram uma renovação nos processos de produção de subjetividade.

A exemplo disso, pode-se considerar a Política Nacional de Humanização (PNH) que é uma política transversal traduzida em ações nas diversas práticas de saúde e esferas do sistema caracterizando uma construção coletiva. Através dela, uma mudança da cultura da atenção aos usuários e da gestão dos processos de trabalho produziram diálogos fecundos e uma renovação das práticas (BRASIL, 2004).

Por outro lado, o Ministério da Cultura vem efetivando, através de Programas Culturais, um novo cenário de sustentabilidade para as proposições culturais, inserindo a participação de populações em situação de vulnerabilidade social, excluídas do exercício de direitos à cultura. São proposições políticas que visam garantir o acesso dos cidadãos aos meios de formação, criação, difusão e fruição cultural (BRASIL, 2005).

Nesse sentido, nossas parcerias são práticas de intervenção social que propõem soluções criativas e participativas para a melhora das condições de vida da população e de comunidades, operam estratégias que afirmam um compromisso público e inscrevem, no acompanhamento de sujeitos, traços de singularidade e experiências de diversidade.

A experiência do PACTO traz a possibilidade de marcar a produção de tecnologias socioculturais de participação da população em vulnerabilidade social, e tem contribuído para efetivação dessas políticas públicas nos diferentes locais de inserção de suas ações práticas e colaborações efetivas. Além disso, num movimento de retro-alimentação, essa proposta tem aprofundado suas ações e reflexões a partir da produção conceitual e prática engendrada pelas políticas referidas, e tem acompanhado mudanças no cenário de participação sociocultural e, efetivamente, tem cultivado uma colaboração na formação de estudantes e profissionais de TO.

A nova formatividade das vidas em conexão gerou novos projetos, novas redes vinculares, novos fazeres, novas possibilidades de participação sociocultural, constituiramse novos rizomas na malha cultural: o que envolve novas visualidades, agenciamentos e trocas. Forças produtivas vão se tornando disponíveis, novas linguagens e narrativas ganham forma. Aqui encontramos fortalecimento clínico, artístico e social, acompanhamento de processos de vida e embates com o território da cultura (CASTRO, 2006).

CASTRO, E. D. de; INFORSATO, E. A.; ANGELI A. do A. C. de; LIMA, E. M. F. A. Education in occupational therapy in the art \& health interface: the PACTO experience. Rev. Ter. Ocup. Univ. São Paulo, v. 20, n. 3, p. 149-156, set./dez. 2009.

ABSTRACT: This paper presents the education work offered in the Occupational Therapy Program developed by the Laboratory of Studies and Research in Art, Body and Occupational Therapy of FMUSP. The Laboratory conducts teaching and research activities, in the didactic-assistancial field, with groups and individuals accompaniment for heterogeneous population through the Artistic Compositions and Occupational Therapy Permanent Program (PACTO) and through partnerships made with projects in the art/health interface. Students experiences are sheltered and elaborated in team discussion, weekly supervisions, study groups and theme-deepening seminars. The education qualifies students to: understand and build up practices in the art/health interface under an occupational therapy's perspective; questioning the approaches in the art/health interface in healthcare spaces and in cultural spaces; comprehend social and institutional relations and institutional transformation processes; understanding the occupational therapists' participation in cultural policies and health humanizing policies. We chose to report and scoring aspects of the work done in recent years (2003-2008) in which some teaching strategies were consolidated and showed its effects on students' education and professional exercise. In the Occupational Therapy field there is an increase in the possibilities for professional performance linked to the issues of cultural production, in trans-disciplinary projects dealing with constructing inclusive social networks, with collective participation and production of subjectivity.

KEY WORDS: Occupation therapy. Education. Art. Health human resource training. 
CASTRO, E. D. de et al. Formação em TO. Rev. Ter. Ocup. Univ. São Paulo, v. 20, n. 3, p. 149-156, set./dez. 2009.

\section{REFERÊNCIAS}

ANGELI, A. A. C. Respiros - por um estado de jogo entre o teatro e a clínica. 2008. 153 fls. Dissertação (Mestrado em Psicologia Clínica) Pontifícia Universidade Católica de São Paulo. São Paulo, 2008.

BRASIL. Ministério da Saúde. Secretaria Executiva. Núcleo Técnico da Política Nacional de Humanização. HumanizaSUS. Política Nacional de Humanização. Brasília, 2004.

BRASIL. Ministério da Cultura. Plano Nacional de Cultura. Brasília: Ministério da Cultura, 2005.

CASTIGLIONI, M. C; CASTRO, E. D.; LIMA, E. M. F. A.; SILVA, S. M. P., et al. Análise de atividades: apontamentos para uma reflexão atual. In: DE CARLO, M. M. R. P.; LUZO, M. C. de M. (orgs.). Terapia ocupacional: reabilitação física e contextos hospitalares. São Paulo: Roca, 2004.

CASTRO, E. D. Arte, corpo e terapia ocupacional: aproximações, intersecções e desdobramentos. Rev. de Ter. Ocup. Univ. São Paulo, v. 11, n. 1, p. $7-12,2000$.

CASTRO, E. D. Atividades artísticas e terapia ocupacional: construção de linguagens e inclusão social. 2001. 326fls. Tese (Doutorado). Escola de Comunicação e Artes da Universidade de São Paulo. São Paulo, 2001.

CASTRO, E. D. A compreensão do uso de atividades na perspectiva do PACTO - Programa Permanente Composições Artísticas e Terapia Ocupacional. In: Simpósio de Terapia Ocupacional FMRP USP, 2. Palestra. Ribeirão Preto, outubro de 2006.

CASTRO, E. D.; FONSECA, F. V. D.; SAITO, C. M. Relatório científico projeto "Corpo e Arte: articulando ações em Terapia Ocupacional”. Relatório Parcial FAPESP período 01/08/2004 à
30/07/2005. São Paulo, agosto, 2005.

CASTRO, E. D.; FONSECA, F. V. D.; SAITO, C. M. Os ateliês de corpo e arte em terapia ocupacional: lugares de produção de vida e de participação sócio-cultural. In: Anais do X Congresso Brasileiro de Terapia Ocupacional. Goiânia, maio, 2007.

GUATTARI, F. Caosmose: um novo paradigma estético. Rio de Janeiro: Ed. 34, 1992.

INFORSATO, E. A. Clínica Barroca: exercícios de simpatia e feitiçaria. 2005. 169 fls. Dissertação (Mestrado).Pontifícia Universidade Católica de São Paulo. São Paulo, 2005.

LIMA, E. M. F. A. Das obras aos procedimentos: ressonâncias entre os campos da Terapia Ocupacional e das Artes. 2003. 344 fls. Tese (Doutorado) São Paulo, Pontifícia Universidade Católica de São Paulo. São Paulo, 2003.

LIMA, L. J. C. Viver e envelhecer com qualidade: interfaces da Terapia Ocupacional, atividades artísticas e gerontologia. 2005. 210fls. Dissertação (Mestrado). Pontifícia Universidade Católica de São Paulo. São Paulo, 2005.

MATURANA, H.; VARELA, F. A árvore do conhecimento. São Paulo: Palas Athena, 2001.

MORIN, E. In: Carvalho, E. de A. A declaração de Veneza e o desafio transdisciplinar. Rev. Margem, p. 91-103, 1992.

SANT'ANNA, D. B. Passagens para condutas éticas na vida cotidiana. In: Corpos de passagem: ensaios sobre a subjetividade contemporânea. São Paulo: Estação Liberdade, 2001.

SARRACENO, B. Libertando identidades: da reabilitação psicossocial à cidadania possível. Rio de Janeiro: Instituto Franco Basaglia/Te Corá, 1999. 